\title{
Technical cross-fertilization between terrestrial microgrids and ship power systems
}

\author{
Robert E. HEBNER ${ }^{1}$ - Fabian M. URIARTE ${ }^{1}$ - Alexis KWASINSKI ${ }^{2}$. \\ Angelo L. GATTOZZI ${ }^{1}$ Hunter B. ESTES ${ }^{1} \cdot$ Asif ANWAR $^{3}$. \\ Pietro CAIROLI ${ }^{3}$ - Roger A. DOUGAL ${ }^{3}$ - Xianyong FENG $^{4}$. \\ Hung-Ming $\mathrm{CHOU}^{5}$ - Laurence J. THOMAS ${ }^{6}$ Manisa PIPATTANASOMPORN ${ }^{7}$. \\ Saifur RAHMAN ${ }^{7}$ - Farid KATIRAEI ${ }^{8}$ - Michael STEURER ${ }^{9}$. \\ M. Omar FARUQUE ${ }^{9}$ Mario A. RIOS ${ }^{10}$ - Gustavo A. RAMOS ${ }^{10}$. \\ Mirrasoul J. MOUSAVI ${ }^{4} \cdot$ Timothy J. MCCOY ${ }^{11}$
}

\begin{abstract}
Aspects of terrestrial microgrids and ship power systems are examined. The work exposes a variety of technical synergies from these two power systems to effectively advance their technologies. Understanding their overlap allows congruent efforts to target both systems; understanding their differences hinders conflict and redundancy in early-stage design. The paper concludes by highlighting how an understanding of both systems can reduce the investment in research resources.
\end{abstract}

CrossCheck date: 28 May 2014

Received: 14 May 2014/Accepted: 3 March 2015/

Published online: 27 May 2015

(C) The Author(s) 2015. This article is published with open access at Springerlink.com

$\triangle$ Robert E. HEBNER

r.hebner@ieee.org; r.hebner@cem.utexas.edu

1 Center for Electromechanics, The University of Texas at Austin, Austin, TX, USA

2 Department of Electrical and Computer Engineering, University of Pittsburgh, Pittsburgh, PA, USA

3 University of South Carolina, Columbia, SC, USA

4 ABB Inc., Raleigh, NC, USA

5 Texas A\&M University, College Station, TX, USA

6 Lauren Engineers and Constructors, Inc., Abilene, TX, USA

7 Virginia Tech's Advanced Research Institute, Arlington, VA, USA

8 Quanta Technology, Inc., Raleigh, NC, USA

9 Center for Advanced Power Systems, Florida State University, Tallahassee, FL, USA

10 Universidad de los Andes, Bogotá, Colombia

11 McCoy Consulting, LLC, Montross, VA, USA
Keywords Microgrid, Power systems, Ship power systems

\section{Introduction}

This paper examines operational and research topics of two related applications: terrestrial microgrids and ship power systems. While fundamental concepts in the areas presented are well understood, the challenges of porting engineering experience from large-scale terrestrial systems having large spinning reserve, size, and weight to small-scale systems with much less flexible parameter spaces is challenging.

As far as being smart systems (i.e., systems designed with intelligent control), ship systems have an incentive to lead land-based systems. This is due to the fact that system failure is more critical for ships than it is for terrestrial systems. For the safety of the passengers and/or crew, ships are designed to achieve maximum reliability. For terrestrial systems, the stakes have not been quite so high. Outages are typically infrequent and those that cannot be fixed automatically can usually be repaired by a maintenance crew within hours.

The situation for terrestrial grids is changing, however. One of the important factors stimulating this change is distributed generation, including solar panels. Bidirectional power flow provides an incentive to improve distribution automation.

\section{Land-based microgrids}

Microgrids are electrically and geographically small terrestrial power systems capable of operating connected to, or islanded from, a national grid. The islanding 
capability of microgrids imposes strict requirements such as energy independence and service quality for an extended period. Installed microgrids capacity is expected to grow to be three to four times larger in the next three years [1].

An emerging trait of microgrids is the penetration of renewable energy at distribution-level voltages (typically below $35 \mathrm{kV}$ ). The availability of this technology is of interest to several private and public entities-but in particular to the U.S. Department of Defense (DOD) and U.S. Department of Energy (DOE). In 2008, DOD and DOE announced their intent to make military installations netzero energy to the grid-installations that produce as much energy (on or near them) as they consume. This energy can come from renewable sources or from fossil fuels. In 2009, the US Navy responded to this goal by mandating that by $2020,50 \%$ of the Navy's energy consumption will come from renewable energy sources.

The power demand for military bases tends to be about $50 \mathrm{MW} \pm 25 \mathrm{MW}$. Consequently, bases have power systems of similar electrical sizes to ships. Additionally, programs such as the More Electric Aircraft program in the US Air Force and the Electric Ship Research and Development Consortium funded by the Navy have, over the past decade, significantly improved the technology underpinning and the ability to model and control power systems of the size of bases. Thus, the DOD has the technical resources to improve its own systems. However, since the DOD has tended to outsource the operation of its base electrical power systems to the local utility or others, there are administrative barriers to using its knowledge and experience to improve its own energy security.

\section{Ship power systems}

Shipboard electric power systems range from as small as a few MW up to future plans for nearly $100 \mathrm{MW}$. While most ships built today feature mechanical propulsion and a separate electric power system, for more than 20 years, there has been a trend towards integrated electric propulsion where a single set of generators provides electric power for both propulsion and other loads aboard the ship. For commercial ships, this trend is driven by the need to improve fuel efficiency in light of ever-increasing fuel prices as well as the requirement to meet the MARPOL Annex VI emissions regulations [2].

For military ships, movement towards all-electric architectures is driven by efficiency, survivability and the anticipated development of high-powered sensors and weapons. The advantages of going to an all-electric ship include reduced manning, versatility to respond to future needs, and higher energy efficiency.
Due to their isolated nature, one important aspect of electric ship power systems is a high level of redundancy. Even though it is a power system of less than $100 \mathrm{MW}$, it may have between two and 10 generators of various sizes to provide that power. This redundancy permits choosing a correct set of generators to efficiently power and support large dynamic loads.

A ship power system is, in every sense, a microgrid. It contains generation, distribution, and loads. At sea, it is an isolated, self-sufficient power system. At the dock, it plugs into shore power and becomes part of the terrestrial grid. So experience with shipboard power systems can aid in the design and operation of terrestrial microgrids.

\section{Technical synergies}

This section examines select aspects of microgrids and ship power systems. While a wide range of technical aspects could be addressed, the subset below focuses on current research trends.

\subsection{Voltage level}

The choice of voltage level, type (AC and/or DC), and frequency is of primary importance to the design of microgrids and electric ships. Such criterion constitutes a fundamental basis that defines many other electrical system parameters, such as size, weight, cabling, cost, losses, load flow, safety, protection schemes, electrical interfaces, grounding, stability, and efficiency.

Electrical systems that operate only in island mode do not have a National Electric Code (NEC) voltage standard that must be followed [3]; so isolated microgrids and electrical ship-based power systems can choose to optimize performance as necessary. However, as these systems interface occasionally with larger terrestrial grids, the interconnection voltage and frequency influence the underlying microgrid or ship bus voltage level. Moreover, the commercial availability of equipment designed for specific voltage classes is an important financial factor when considering non-standard voltage classes for standalone microgrids or ship systems.

\section{1) Microgrids}

For terrestrial microgrids, DC-based systems are becoming a common choice due to the proliferation of DCbased loads such as computers and electronic devices, lighting (both compact fluorescent and light-emitting diodes), variable frequency drives, and electric vehicles. Furthermore, distributed generation systems like solar 
arrays, micro-turbines, and fuel cells are inherently DCbased or high frequency. In addition, many energy storage technologies are inherently DC-based and can increase both reliability and power quality in the event of brief supply disturbances.

Existing voltage platforms include the traditional $48 \mathrm{~V}$ DC power distribution system used in the telecommunications arena, a proposed $24 \mathrm{~V}$ DC by the EMerge Alliance, and a wide range of other voltage levels culminating in a threshold between 380 and $400 \mathrm{~V}$ DC [3-7]. The $380 \mathrm{~V}$ voltage level is a recommendation agreed upon by a joint study between Ecos Consulting, EPRI, and Lawrence Berkley National Laboratories, which suggests 380 V DC provides for optimal energy efficiency in power delivery to data centers [4-6]. There is also an IEC study group developing a world standard for $380 \mathrm{~V}$.

\section{2) Ships}

For the Navy's next generation of all-electric ships (AES), the Office of Naval Research (ONR) has tasked the Electric Ship Research and Development Consortium (ESRDC), a multidisciplinary team formed from eight major research universities [8], to provide options and recommendations. A major goal of the ESRDC is to evaluate the electric, thermal, mechanical, structural, and hydrodynamic aspects of an electrical ship power system, and based on this evaluation, recommend options with costs and benefits clearly defined. The three electrical designs studied to date are medium voltage DC (MVDC), $60 \mathrm{~Hz}$ AC (MVAC), and higher-frequency AC systems (HFAC). While many of today's ships utilize low voltage $(450 \mathrm{~V}, 60 \mathrm{~Hz} \mathrm{AC})$ distribution, future all-electric ships will likely feature a medium voltage primary distribution system with low voltage AC and DC provided to the loads.

Each system has been assessed with respect to a number of metrics such as power demand and variability, dynamics and balancing, energy storage, propulsion system needs, mission system needs, critical loads, load-shedding, reliability, redundancy, efficiency, faults, control systems, size, weight, volume — and very importantly—power density.

\section{3) Cross-fertilization}

Comparing voltage classifications between microgrids and ships, terrestrial microgrids are guiding standard practice and design in terms of development, industry standardization, and engineering experience. This is, perhaps, due to historical references from the telecommunications industry, migrating and refining their protocols to data centers. Ships have relied on both established commercial and military interface standards $[9,10]$ with newer ones being developed for the more advanced architectures [11].

\subsection{Frequency}

Frequencies other than 50 or $60 \mathrm{~Hz}$ are being considered for microgrids and ships. Advantages and disadvantages of such migration are discussed here.

\section{1) Microgrids}

Microgrids, when in island mode, have the choice of frequency. This choice is influenced by operational costs, reliability, energy security, and distribution efficiency. Other important factors are the presence of energy storage and renewable energy technologies, which are mainly in DC form, suggest distributing in this configuration. Common examples of DC microgrids are data centers, where it has been argued [12] that improvements in air conditioning operation through combined heat and power cycles, and simpler power distribution chains, can increase efficiency by as much as $30 \%$ [13]. While data centers are not good surrogates for ships, the results suggest careful examination of the advantages of DC on ship power systems is appropriate.

Although there is frequency independence, microgrids that operate at least some of the time connected to grid (e.g., a university campus) are likely to preserve the $50 \mathrm{~Hz} /$ $60 \mathrm{~Hz}$ to avoid the cost of frequency conversion. This trend is reinforced due to the fact that the large use of $50 \mathrm{~Hz} /$ $60 \mathrm{~Hz}$ equipment drives down its cost compared to equipment operating at other frequencies. In addition, operation at a single frequency is expected to reduce training and maintenance costs.

\section{2) Ships}

Ship power systems predominantly operate at $60 \mathrm{~Hz}$ due to the economy afforded from leveraging industrial power equipment for shipboard application.

In recent years, alternative frequencies for future warships have been considered. Both higher-frequency AC (HFAC) and DC have been the topic of much research by the ESRDC. The motivations of HFAC $(240 \mathrm{~Hz}$ herein [14, 15]) include power system, weight, and volume reductions achieved by reducing the size of magnetic components and enabling the use of high speed turbine-generator sets. Disadvantages of HFAC systems include increased electrical losses, stray currents, and the installation of converters to support $60 \mathrm{~Hz}$ loads, including shore power.

The specific frequency of $240 \mathrm{~Hz}$, may not be optimum, but it can easily be generated by choosing an appropriate number of poles in the high power generator. In addition, it is low enough so that the losses are likely acceptable and no line compensation is need for the typical line lengths in ships, less than a few hundred meters.

Additionally, to support high-powered HFAC, new design principles and standards would have to be 
developed. It is unlikely the terrestrial microgrids will adopt this frequency because terrestrial loads are mainly $60 \mathrm{~Hz}$ or DC, but aircraft, having even greater weight constraints, have operated at $400 \mathrm{~Hz}$ for decades.

The interest in DC systems on ships is the same as it is in terrestrial applications, i.e. to increase efficiency and reduce weight and volume. The promise for improved efficiency is based largely on fewer frequency conversions. Generators at the appropriate power levels tend to operate at $\mathrm{AC}$ while loads increasingly require DC power. This characteristic of the loads may lead to a DC system being more efficient.

A DC system may be smaller than an equivalent $50 \mathrm{~Hz} /$ $60 \mathrm{~Hz}$ system due to such factors as converters reducing the need for high power circuit breakers. Another promising attribute is that the high switching frequencies in converters require smaller passive components than would a $50 \mathrm{~Hz} / 60 \mathrm{~Hz}$ operating system.

It has not yet been demonstrated that either of these options produces benefits at the system level. While it is relatively straightforward to assess the benefits of individual components and subsystems operating at different frequencies, it is more difficult to assess a complex full system. Numerous full ship designs and tests will be needed to determine which power frequency will offer the best combination of efficiency and small size in the future.

\subsection{Design and operation}

This section presents a description related to design and operation of microgrids and ship power systems.

\section{1) Microgrids}

In a terrestrial microgrid, fossil-fuel-based generators are generally used in conjunction with energy storage devices to serve mission-critical facilities that require continuous operation. Fossil fuel-based generators may include internal combustion engines running on diesel, natural gas, or both, microturbines, or fuel cells. Energy storage devices may include battery energy storage or flywheel energy storage.

For fossil fuel-based generators, the size of distributedenergy-resource units should be at least the same size as the critical assets $(\mathrm{kW})$. The type of generators to be deployed will depend on fuel availability onsite. Usually, it takes less than $30 \mathrm{~s}$ for the generator to start up to serve critical loads. During the generator start up, energy storage devices can be used to secure critical loads to allow a smooth transition from the grid-connected to islanded-mode operation.

For energy storage devices, the power rating should be selected to cover the demand of the critical loads $(\mathrm{kW})$ to be served during the transition. The stored energy $(\mathrm{kWh})$ will depend on the requirement of how long to secure the critical assets. Renewable energy can be integrated into a microgrid as well, depending on the load profile and resource availability.

In a grid-connected operation, a microgrid intelligent control and management system can be programmed to minimize the operating cost of a microgrid, typically by shaving the peak demand to avoid high electricity prices during peak hours. For a system with renewable energy sources, those sources should be utilized as much as possible. In most cases, there is a limit on the number of hours a diesel generator can run in a given year for peak-shaving purposes. For example, in North Carolina, this limit is $250 \mathrm{~h} /$ year, whereas in California this limit is $40 \mathrm{~h} /$ year.

For battery energy storage, it is necessary to carefully plan for the storage unit's charge and discharge schedule to maximize storage use. Demand response can contribute to additional peak demand reduction by deferring certain noncritical loads during grid-connected operation [16-18].

One of the main characteristics of a microgrid is its ability to offer energy security improvements of a local electrical power system through operation in an islanded mode [19]. Transitions to the islanded mode can be a scheduled event, e.g., initiated by a customer to isolate it from the grid during bad weather conditions, or an unscheduled event, e.g., initiated by loss of area voltage or frequency.

\section{2) Ships}

While a terrestrial microgrid has two modes of operation, grid-connected and islanded modes, ships function in islanded mode when underway with no option to operate as grid-connected. Therefore, installed generating capacity must be sized to be able to serve the peak demand on the ship, including a service life growth margin.

While not as common as with terrestrial microgrids, renewable energy systems (mainly PV) are beginning to appear on ships. Since such generation is highly reliable and predictable, some high value loads can be designed to be served by PV generation. Some battery storage may also be considered to make these loads fully autonomous. Also, there is no limitation on the number of hours a generator can run, however, commercial ships are subject to IMO regulations for both $\mathrm{CO}_{2}$ and $\mathrm{NO}_{\mathrm{X}}$ emissions. For a ship power system, load shedding is a necessary element to allow the disconnection of nonessential loads, thereby allowing critical loads to be served during an emergency situation. Such a situation can occur when one or more online generators unexpectedly fail, causing a sudden overload condition. This will result in overloading of the remaining online generator(s).

Today, load shedding schemes are usually determined during the ship's design utilizing a simplistic single or multiple staged scheme [20]. 
It is anticipated that in future ships, load shedding will be much more dynamic, permitting the ship's crew to readjust the load profile in real time to adapt to the changing situations in which they may find themselves.

\section{3) Cross-fertilization}

During an islanded condition, load and generation must be balanced at all times. In a typical microgrid, since locally available generation is sized to cover critical loads, non-critical loads must be shed either manually or automatically, depending on their system design and set up.

Unlike terrestrial microgrids, where load shedding is usually initiated by under-frequency relays, load shedding in ship power systems relies on real power (watt) sensors that monitor generator outputs. That is, generator outputs are constantly monitored and when a load exceeds a certain percentage of its rating for a certain period of time, a preselected load-shedding scheme is activated.

A critical difference is that in a land-based system, the power provider frequently does not own the loads so load shedding is a negotiation, generally done in advance, or a complete shutdown is necessary. On a ship, the entire system, including all loads, is owned by the same organization; so load shedding requires less negotiation. However, new research is necessary to do a cost-benefit analysis of added generation capacity on the ship to serve additional loads. There may be high value loads on the ship that need service during critical times. The value of serving such loads needs to be studied against the cost of additional generation, including related environmental restrictions.

\subsection{Generation}

There are more books on synchronous generators than on any other power apparatus [21]. While it is not possible to cover the breadth of this subject, it is important to highlight basic traits of generation on microgrids and ships.

\section{1) Microgrids}

Local microgrid generation is usually interconnected at a low voltage (600 V and below, but there may be exceptions), and can be controlled independently of the terrestrial grid. Microgrid generation sources include conventional generating units as well as non-conventional ones like fuel cells, wind, solar, and other sources, all of which are known as distributed generation (DG).

DG reduces the amount of energy lost in transmitting electricity, because electricity is produced near where it is consumed. In addition, it permits additional power to be delivered to the user without incurring the cost of augmenting the electric power transmission system. Distributed energy sources are small-scale power generation technologies used to provide an alternative to, or an enhancement of, the traditional electric power system. With its advantages, DG also has disadvantages, such as higher cost and some sources (i.e. wind and solar) are not readily dispatchable, due to their stochastic nature. Large scale distributed generation can affect grid-wide functions such as frequency control, allocation of reserves, power quality, voltage stability, harmonics, and protection [22]. These are challenges being solved in Europe today, not for microgrids, but for national grids with significant renewable penetration.

\section{2) Ships}

Ship power systems, like microgrids, are isolated finite inertia power systems. However, on ships, the available generators are the only source of supply for the system loads. Most ship generators are fossil-fueled diesel or gas turbine driven synchronous machines, the exception being the very few ships which are starting to feature renewable sources. The number and size of the generators should be selected to maximize energy efficiency under the most likely operational scenarios. Most shipboard power systems will feature from 2-6 generators, although some cruise ships may have as many as 10 generators. Commercial ships are also required by regulation to include an emergency backup (SOLAS) generator to supply designated emergency loads [23].

The generators supply the primary ship power system, which is predominately $60 \mathrm{~Hz}$ today. Low voltage ship power systems are often three-phase, delta-connected, ungrounded $60 \mathrm{~Hz}$. Since the system is ungrounded, the system can continue to operate if a line to ground fault occurs. A disadvantage of ungrounded systems for ships is that fault-to-hull currents are small and difficult to detect and locate. For personnel safety reasons, MV systems always feature a high impedance grounding system.

One of the advantages of an IPS architecture is the ability to use any generator to power any load on the ship. The more advanced MVDC architecture also enables variable-speed generation, which may provide up to $20 \%$ fuel savings over constant speed generators required on $\mathrm{AC}$ distribution systems.

\section{3) Cross-fertilization}

The generation system of both microgrids and ships are sized to provide power to small power systems. In the case of microgrids, generation can be in the form of conventional generators (e.g., diesel sets, turbine-driven generators) or generation powered from renewable resources (e.g., small windmills or photovoltaic cells. Although many forms of generation exist for ships, it is common to deliver power through gas-turbines and/or diesel-based generators working in unison to support both vital and non-vital loads. 


\subsection{Load types}

Loads may well be the ultimate driver of electric power system architectures. Thus, if differences and similarities exist between terrestrial microgrids and ship power systems, in the final analysis these are due in large by the loads they serve. Therefore, there is merit in examining the two systems from a load-centric perspective [24-26].

\section{1) Microgrids}

The loads of terrestrial microgrids do not differ significantly from those of the larger local or national grid: the difference lies in the scale and number rather than in types and characteristics.

Fully recognizing the fact that microgrids themselves can range from very small systems ( $\mathrm{kW}$ level) to fairly large ones (MW level), in general, the following attributes can be identified for their loads:

a. Loads tend to be conventional and have similar electrical characteristics

b. Loads tend to be continuous rather than intermittent, typically varying on time scales of minutes to hours

c. No single load is dominant

d. Individual loads are turned on and off in discrete increments, but their cumulative total remains a rather smooth and slowly varying function of time

e. Total system load tends to be predictable based on past experience with good accuracy

\section{2) Ships}

A congruent list is made for loads on ship power systems, contrasting those found today with those expected in the future:

a. Today, ships feature predominately conventional loads. In the future, a wide variety of loads is expected, from conventional to those with unusual characteristics

b. Some of these future loads may be intermittent, operating on time scales down to milliseconds or less, and can range in power from small $(\mathrm{kW})$ to very large (MW or even GW)

c. Generally, as with microgrids, no loads dominate, with the exception of propulsion loads. These can reach $90 \%$ of the installed power capacity on-board. However, propulsion is easily controlled so as to not adversely affect the grid's stability

d. In the future, some loads (i.e. an electric gun) can even exceed installed capacity for short duration pulse duty operation

e. The total cumulative load can exhibit fast transients and does not necessarily evolve smoothly in time
3) Cross-fertilization

It is clear from the lists above that the differences between microgrids and ship power systems will become significant. As is often true in such cases, the opportunities for cross-fertilization are limited and likely asymmetrical, proceeding from the more esoteric to the more conventional.

Below is an initial, and certainly non-exhaustive, list of predictable "lessons learned" that will cross over from one field to the other.

From ships to microgrids:

a. Control strategies to ensure power quality and stability margins in situations where the installed power capacity is only minimally larger than the total power demanded by all loads

b. Interfacing sections of the grid with different voltage and frequency characteristics

c. Managing the ever growing density in the power system of power electronic conversion stages

d. Development of flexible architectures with sufficient redundancies suitable for quick reconfiguration in response to possible damage

From microgrids to ships:

a. Utilization and integration of renewable energy resources to supplement traditional ones

b. Control system based on decentralized intelligence and decisional autonomy

c. Understanding hotel-load demand and uncorrelated behavior from civilian sector consumption data

d. Engineering criteria on the selection of storage type, location, and size based on experiences ashore

e. Strategies to integrate auxiliary energy storage units to supply intermittent loads to avoid overloading the grid

\subsection{Dynamic balancing}

Dynamic balancing is an important function in microgrids and ship power system operation. Microgrids and ship power systems have limited generation capacity and finite inertia, and as a result, may destabilize or become overloaded following a disturbance.

Dynamic balancing strategy regulates generation output and controllable load demand to match while satisfying operational constraints in operational real time. (The decision time step of a dynamic balancing strategy for finite inertia systems typically occurs on the order of $10-100 \mathrm{~ms}[27,28])$. The balancing strategy is an effective tool to improve system-level stability on finite inertia power systems, which is an important consideration in early-stage microgrid and ship power system design studies. 


\section{1) Microgrids}

Microgrids can incorporate a large number of intermittent energy resources, such as wind and solar, for which generation capacity varies significantly depending on the weather $[29,30]$. Moreover, a large number of plug-in electric vehicles (PEVs) will be integrated into residential and commercial microgrids [31] for which charging events will likely cause frequency and voltage oscillations in such limited inertia systems. In addition to these potential destabilization trends, the transition of microgrids from grid connected mode to island mode may overload the microgrid's generators. Thus, dynamic balancing strategies are important to match generation and load in a system with renewable energy intermittency and high penetration of PEVs.

When sudden load or generation changes happen in microgrids, dynamic balancing strategy regulates setpoints of generators or controllable loads to reduce the mismatch during the transient state. This mitigates frequency and voltage oscillations in the system. However, combustion generation units, such as diesel generators and micro-turbine generators, cannot quickly respond to these sudden changes in microgrids. This delayed response may result in significant frequency and voltage oscillations. In this situation, energy storage and additional controllable loads can be used to compensate for the generation and load changes in microgrids due to their faster response times. Energy storage devices commonly used for dynamic balancing include batteries, ultra-capacitors, flywheels, and others. Controllable loads typically considered for dynamic balancing include service loads such as washing machines, dryer loads, air conditioning, heater loads, and any other $240 \mathrm{~V}$ domestic load (PEVs included).

Existing solutions for the dynamic balancing problem in microgrids include secondary frequency regulation, secondary voltage regulation, and emergency load shedding. Since dynamic balancing is a secondary control problem in microgrid operation [32], a dynamic balancing strategy must make decisions from measurements and communications to coordinate various electrical components in microgrids to achieve group objectives within a decision time step of $10-100 \mathrm{~ms}$ to ensure system-level stability of microgrids.

\section{2) Ships}

The ship power system is another type of finite inertia power system. Battle damage and sudden increase in the load demand (e.g., pulsed loads, high-energy weapon loads) can overload the generators. In addition to generation overload, this type of system has a large portion of nonlinear and dynamic loads, which can account for a high percentage of the generation capacity-this further reduces the stability margin. For example, the propulsion loads of anticipated all-electric ships can consume $90 \%$ of the generation capacity [33].

An added constraint to dynamic balancing strategy is the requirement for operation in real time to maintain system frequency and voltage at nominal values. Since generators respond slowly to disturbances, sudden load changes can cause large frequency or voltage deviations, which may trip sensitive equipment or other loads or generators in the system.

Similar to controllable loads in microgrids, energy storage systems and noncritical loads, such as propulsion loads (in certain operation modes) and non-vital service loads, can be employed as resources to compensate sudden changes in ship power systems. Realistically, however, the ship propulsion load on IPS ships is typically managed to maintain stability.

\section{3) Cross-fertilization}

Dynamic balancing for microgrids and ships were compared. In the former, dynamic balancing is achieved by adjusting generation set points and managing controllable loads. In the latter, balancing is also achieved by adjusting generation set points and managing controllable, non-critical loads. An added complexity on ships is that most critical loads in ships include two redundant supply paths. When the normal path of a critical load is damaged, the alternative path can continue to supply power to the critical load. While in principle the strategies are similar in both cases in that they seek voltage and frequency stability in real time, the fundamental difference lies in the vital nature of the loads and stability margins (e.g., microgrids do not anticipate having a single high power dynamic or high energy pulse loads).

\subsection{Stability: part 1}

Current practices on interfacing heterogeneous sources and loads to microgrids and ships are discussed. Although more common in ships, the increasing presence of constant-power loads in small power systems presents increased challenges to classical stability-control paradigms.

\section{1) Microgrids}

In most terrestrial microgrids, both with $\mathrm{AC}$ or $\mathrm{DC}$ power distribution, it is expected that onsite generation units will connect to the local distribution grid through power electronic converters. Typically, the function of these converters is to regulate the voltage at the microgrid distribution bus to which the generator unit is connected. Exceptions of non-converter sources are observed in some $\mathrm{AC}$ microgrids with conventional AC generators driven by 
internal combustion engines, e.g., diesel or biofuel engines. Nevertheless, it is still possible to find other local sources (e.g., microturbines) that require a power electronic interface - or it may be desirable to add a power electronic interface for internal combustion engine-driven sources to have flexible and reliable control.

Power electronic circuits are also expected to be used in order to interface a main power grid to the microgrid. This power electronic interface is not required in $\mathrm{AC}$ microgrids as it is in DC microgrids. Still, power electronic interfaces may be used in AC microgrids to achieve a more flexible control of the power flow in between the main grid and the microgrid. One example of the advantages of having more flexible control is found in the microgrid in [34], where a power electronic interface between part of the microgrid and the main grid serves to provide multiple power quality levels within the microgrid area.

Regarding loads, there will be power electronic converters between the microgrid distribution buses and the loads. The function of these power electronic converters is to condition the electrical signal for the load and to provide decoupling capabilities, e.g., in terms of voltage variations during transients. In many modern loads, such as computers, power electronic interfaces are already present and cannot be avoided. Even in some conventional AC loads, such as induction motors, it can be expected that power electronic interfaces may be added to control speeds or improve efficiency. As a consequence, terrestrial microgrids are expected to have a distributed power architecture in which areas with different voltages are interfaced through power electronic converters.

One of the characteristics of distributed power architectures is the existence of constant-power loads. The constant-power characteristic is due to the power electronic converters interfacing the loads. From a small signal perspective, constant-power loads present negative dynamic impedance that introduces a destabilizing effect into microgrid bus voltage regulating converters. When the main bus regulating converters are not properly controlled, or other features are not included in DC microgrids, it is possible to observe large voltage oscillations or voltage collapse [35]. Some of the alternatives presented to address these instabilities are to include proper filters in the distribution grid, add energy storage, or use adequate controls in the power electronic interfaces at the output of the local generation units [35]. Suitable controls for DC-DC converters include PID [36, 37] and linear-geometric controllers [38, 39].

\section{2) Ships}

Electric ships are expected to have distributed power architectures. While today most loads can be considered traditional, there is a trend towards more power electronic interfaces. Propulsion motors will also be connected to the power distribution system through adjustable speed drives, making them behave as a large constant-power load.

Control approaches on ships are similar to those in terrestrial microgrids. While most ships today do not feature large energy storage, this is seen as a key enabler for the emerging pulse loads such as weapons and high power radars being developed for warships.

\section{3) Cross-fertilization}

Stability characteristics of terrestrial microgrids and electric ships are similar. Since both are likely to have distributed power architectures, the presence of constantpower loads may introduce destabilizing effects into the system. Ships may have a greater proportion of constantpower loads than linear loads when compared to terrestrial microgrids, which make it challenging to design practical stabilizing strategies for ships. The destabilizing effects are more severe for both ships and microgrids as the constantpower load to linear-load power ratio increases. It should be emphasized that this stability concern is a design constraint, not a fundamental problem with the approach.

However, due to their simplicity and robustness, boundary controllers can be applied in both environments. Boundary controllers designed for electric ships provide faster dynamic responses than PID controllers. This is a commonly sought characteristic for terrestrial microgrids to achieve fast compensation of generation or load changes (more in section 4.60 above).

\subsection{Stability: part II}

Stability merits additional attention, as it is one of the metrics deciding future architectures for forthcoming allelectric ships. The previous section gave insight on stability from a (constant power) load perspective. This section examines stability from a reactive-power availability perspective.

\section{1) Microgrids}

The main feature of microgrids is the ability to operate with and without connection to the utility grid. It also allows peer-to-peer and plug-and-play modeling for each component [40]. Most sources are connected to the system through power converters, especially inverters. The control strategies to parallel these power converters play an important role in the stable operation of microgrids [41]. How to distribute the active power and reactive power demand among the parallel inverters is a challenge [42]. In island mode, only local sources can provide the frequency and voltage regulation, which can cause frequency instability and voltage instability. 
Frequency stability is the ability of the system to maintain operation quite near the normal frequency under perturbation [43]. Due to the amount of renewable energy sources connected, the generated power is intermittent. Moreover, unlike synchronous generators that contribute to the inertia of the system, renewable energy sources are frequently connected through power converters. The effective inertia of the system is reduced [44]. Therefore, when the system undergoes disturbance, a large frequency deviation can occur.

Another stability issue is voltage stability-the ability to maintain acceptable voltages at all buses in the system under normal operation and after being subjected to disturbance [45]. Voltage instability results when the reactive power demand is not met. In island mode, reactive power is provided by the inverters that are connected to sources. The available reactive power depends on the design of the inverter and its controller. If the reactive power demand increases to levels the system cannot support, the system will be prone to voltage instability.

\section{2) Ships}

Common traits of ship power systems are that they (1) are isolated power systems; (2) have finite inertia; and (3) are highly coupled systems due to short cable length.

Frequency stability is the main concern in the ship power system, because the system is an isolated power system, and there is no outside frequency reference or power source to maintain the frequency level. All the loads have to be supplied from the generators on the ship. Moreover, the inertia of the system is small compared to terrestrial power systems, so the frequency deviation due to the power mismatch between generation and consumption will be large. In addition, pulse loads, which consume large power in a short time, would result in the large frequency deviation if no proper control strategies are applied [46]. Proper design, however, can eliminate this issue.

Another concern is the voltage stability. In ship power systems, voltage instability occurs when the exciter of the generators hits the limit and the generators cannot provide any more reactive power. Moreover, the predominant load is induction motors, which consume reactive power. When motors start from zero speed or when motors stall, the reactive power demand increases. Also, when the ship is reconfigured, the loading condition may change. In some cases, the loading condition may exceed the capability of the reactive power of the generators.

To tie both sections on stability, it is important to restate that there are several power electronic converters in the system. With these nonlinear, high-bandwidth power converters, the loads supplied by these converters behave as constant power loads. To solve the stability problem created by constant-power loads, known control strategies need to be applied to stabilize the system [47].

\section{3) Cross-fertilization}

From the above discussion, microgrids have more renewable energy sources connected to the system, whereas the energy sources on ships are more controllable. Therefore, the method of solving frequency and voltage stability for ships can use generation and load management. Also, microgrids can get support from the grid in normal operation while the ship operates in isolation mode nearly all of the time. The loads in future ships may include highenergy pulsed-power loads that, unless designed properly, can cause more adverse stability impact. Moreover, reconfiguration occurs more frequently.

\subsection{Power electronic interfaces}

\section{1) Microgrids}

In terrestrial microgrids, the focus on power electronic converters is on the design of distributed energy resources for interfacing local power generation units and energy storage systems. Typical design objectives are oriented toward achieving high-power conversion efficiencies, low cost, and certain operational goals, such as effective implementation of maximum power point tracking for photovoltaic sources. An additional objective is to meet source requirements, such as the need for current source converters for fuel cells [48].

The possibility of finding diverse power sources in hybrid microgrids influences the design of the interfaces for these sources. Moreover, in terrestrial microgrids, it is likely that all sources would be located in a single site that becomes the microgrid's power generation center. In these cases, it is possible to utilize multiple-input converters [49] in order to integrate these heterogeneous sources through the same power conversion modules. Such multiple-input designs are the result of the search for lower cost solutions without compromising system availability [50].

\section{2) Ships}

The design of power electronic interfaces for ships is primarily driven by the goal of achieving high power efficiency and reliability at a low cost, weight, and volume. There are additional requirements that may be more demanding in ships. For example, both conducted and radiated EMI requirements likely may be more stringent in ships than in microgrids.

Today, most shipboard loads are directly connected to the power grid and do not feature power electronic interfaces. However, the number of power electronic interfaces is increasing at a rapid rate. These are mostly variable 
speed drives (VSDs) for the many motor loads found aboard ships. Some other loads such as computers, radars and sonars are inherently electronic in nature.

\section{3) Cross fertilization}

The fundamentals for power electronic circuits and some design goals (e.g., high-power conversion efficiency) are the same in terrestrial microgrids and in electric ships.

Most of the power electronic interfaces found aboard ships today are VSDs, which are derived from industrial drives, both large (i.e. propulsion drives) and small. The proliferation of power electronic interfaces will enable a greater level of load controllability, but will come at the price of the stability issues cited above.

\subsection{Protection issues during load restoration}

The problems associated with load restoration in terrestrial microgrids and ship power systems are similar. Reclosers in terrestrial systems operate in a "single-shot" scheme on live-bus/dead-line post-fault conditions. This operation is known to cause reliability and lifetime degradation due to motor starting and transformer magnetizing inrush currents. Shipboard power systems do not have reclosers. Once a breaker trips, the operator manually investigates the source of the fault prior to attempting to repower any interrupted loads.

In any power system, when faults occur, automatic transfer switches operate to switch between normal and auxiliary sources to maintain service continuity to critical loads. In microgrids, this switching scheme allows operation to continue in islanded mode; in ships, it allows supply of selected loads from auxiliary sources. Henceforth, it stands to reason that adaptive protection settings may allow for more appropriate responses.

\section{1) Microgrids}

In microgrids, there is large unpredictability in loading conditions as it varies widely with time and seasonal changes. Despite the uncertainty in load, an effective "softreclosing" method to mitigate detrimental inrush effects for microgrids has been demonstrated [51]. As the availability of large-scale energy storage at the distribution level is becoming main stream, it is likely that a "bottom-up" approach will mitigate the problems associated with service restorations. For example, intertie protection relays with remote reconfigurability are commercially available and can be used to implement the soft-reclosing method as well.

With large scale energy storage gaining visibility, it appears likely that storage will help mitigate the problems associated with service restorations following an outage.
2) Ships

In ship systems, generation and distribution are confined to smaller areas.

In a ship power network, the difficulty in load restoration arises due to limited redundant sources rather than unpredictability in loading conditions. Although load scheduling and power allocation already work well during normal operation, accidental faults or hostile damage may trigger a situation requiring robust recovery to normal operation. Additionally, where an online generator fails or has been damaged, restart of vital loads such as fire pumps, emergency lighting, and machinery control systems may be difficult and may overload the already precarious power system [52].

Forthcoming energy storage on electric ships may be used to energize the critical loads in a controlled manner followed by a synchronous reconnection with the normal source. This soft-reclosing method for energization-synchronization-reconnection can mitigate the problems associated with switching transients and motor and transformer inrush causing low-voltage conditions in the future.

\section{3) Cross-fertilization}

For terrestrial power systems, switching transients due to asynchronous reclosing spur the failure of protective switching devices and often cause nuisance trips resulting in a failure of the restoration process. Associated with the reclosing transients and motor starting inrush is the delayed voltage recovery effect, which further complicates the restoration process and may lead to under voltage load shedding $[20,52,53]$.

Hence, an approach to mitigate these patterns is sought for both power systems. A system for mitigation in microgrids has been demonstrated in [51].

\subsection{Measurements and communications}

The peculiar characteristics of terrestrial microgrids and ship power systems covered in this paper require a tailored measurement, instrumentation, and communications design to enable the various control and energy management strategies. In general, real-time requirements for measurements and communications are more stringent than what is traditionally known for terrestrial power systems due to the short distances involved, faster dynamics, and rapid fluctuations in power generation and demand.

\section{1) Microgrids}

In terrestrial microgrids, a central controller typically assumes the overall supervisory control and energy management responsibilities. This controller needs to communicate to the local controllers for load and distributed 
generation control in both islanded mode and grid-connected mode. Data collected from local points will be communicated to the central controller and processed in time, and commands may be issued to maintain stability, balance load with generation, or achieve any other energy management functionality as initiated by the operator or automatically by the system. While the propagation delays are not a significant issue due to the short spatial distances involved, the overall communications latency needs to be addressed for proper real-time control and energy management. The overall latency includes the inherent delays in communication nodes, delays due to congestion, and propagation delays. This is in particular important in islanded mode and during the transitions between the two modes where the decision making window for the system controller is much shorter than when there is a grid support for maintaining stability and voltage/frequency regulation. As a result, reliable microgrid designs, operation, and realtime control require an integrated approach considering the reliability and redundancy of the measurement and communications infrastructure.

\section{2) Ships}

The measurement and communications requirements are very similar to terrestrial microgrids - and in some even more stringent applications. Reconfiguration in response to a fault [54], or predictive reconfiguration in response to an anticipated damage or loss of generation, requires synchronized measurements and millisecond decision making and communications to the local actuators. The emerging technologies for faster-than-real-time simulations and modeling can benefit from synchronized measurements and can be proven to be indispensible for reliable operation of an all-electric ship power system.

\section{3) Cross-fertilization}

In measurements and communications, terrestrial microgrids and ship power systems share some common requirements and attributes. Both systems are geographically confined and feature relatively short communications distances. This inherently reduces the propagation delays; however, the overall latency requirements are more stringent at the same time due to faster dynamics and proliferation of power electronic controls. In addition, wireless communication is a good option for land-based systems. It is much more limited in ships, however, as seaworthiness demands that the interior of the hull be divided into isolated water-tight compartments.

Maintaining reliability of supply during normal and emergency conditions requires an integrated approach to design and reliability analysis of both systems, where the intertwined physical and cyber aspects are simulated and studied concurrently. From the operations point of view, both systems can benefit from faster-than-real-time modeling and simulations that enable predictive decision making and control in anticipation for a material event such as sudden change of supply in microgrids or unanticipated system failures.

\subsection{Short circuit fault protection}

A common aspect of microgrids and ship power systems is their behavior when short circuit faults occur. When either system operates in island mode, it constitutes a multi-source power distribution system. The terrestrial system has its sources coupled by electronic power converters, which provide limited power and can limit current emission in case of an overload or faulted condition. Shipboard systems today rely primarily on overcurrent to trip electromechanical circuit breakers.

\section{1) Microgrids}

Microgrids can have multiple power sources. Moreover, due to the heterogeneous mix of sources (e.g., photovoltaic, fuel cell, wind turbine, etc.) and energy storage elements (e.g., batteries, super capacitors, etc.), these are connected to the distribution grid through controllable electronic power converters. Although these microgrid characteristics allow short circuit faults to be fed from multiple sources or storage elements, they also limit the fault current.

The fact that a microgrid is fed from multiple elements provides higher power quality and reliability, but also makes it more difficult to isolate part of the system in case of faults. On the other hand since power sources are connected to the grid through controllable converters, the microgrid can limit fault currents by changing the setpoints of these converters. These considerations open the option of using innovative fault protection methods, such as the one presented in $[55,56]$, that eliminate disruptive currents and provide a rapid reconfiguration of the system.

\section{2) Ships}

Power distribution systems for ships can feature a variety of power sources, renewable sources, and energy storage systems. Conventional generation sources are directly connected to the grid and loads are protected via electromechanical circuit breakers. Energy storage and renewable sources are typically connected via electronic interfaces. Zonal architectures found on some warships, with multiple paths from source to load, present unique challenges for fault protection not found in microgrids.

Future shipboard systems may make more extensive use of controllable power electronic converters to interface with the distribution bus than is found at sea today. The controlled multisource system configuration introduces higher reliability and survivability, and, as in the case of a 
microgrid, it generates new options and challenges in terms of protection against short circuit faults [57].

\section{3) Cross-fertilization}

The presence of multiple sources and power electronics is a common aspect between microgrids and ship distribution systems regarding how short circuit faults evolve and can be located. Another important commonality is the fact that a 10-100 MW microgrid has power level and dimension similar to a combatant ship, which is indicative that the cable impedances between sources and loads are in the same order of magnitude in both power systems. This suggests that fault experiences from both systems can be shared and is an important advantage to research and development of fault protection equipment.

A major distinction between a terrestrial microgrid and a ship power system is the treatment of the ground (i.e., "earth") as a conductor for fault currents. In terrestrial systems, solidly grounded systems dominate for safety reasons and result in relatively high line-to-ground fault currents, which must be interrupted quickly to limit damage to equipment [58]. Ship systems, however, are expected to continue to operate with a single line-to-ground fault present $[11,59]$. This requires ungrounded or high-resistance grounded systems, which pose significant challenges with respect to the design of the grounding system [60, 61] and the identification of ground fault locations [62].

\subsection{Autonomous operation and communication infrastructure}

As a general requirement, autonomous operation is considered a favorable design approach for islanded systems in order to combine the use of passive and active control schemes to provide a certain level of reliability and security. Although communication infrastructure and remote controls play important roles in increasing efficiency and reliability of islanded systems, localized control and operation in an autonomous fashion can prevent cascaded failures and wide-spread power quality issues.

Several existing microgrid designs tend to be based on an autonomous operating approach in which many aspects of the control and operation are performed locally using communication-less controls for power balancing and voltage/frequency regulation [63]. In contrast, because of very compact and precisely defined system boundaries, ship power systems typically use coordinated and remotely controlled schemes. There will always be a tradeoff and challenge in design to establish a balance between centralized schemes and distributed (passive or active) controls. Nevertheless, communication system failure must be considered as part of $N-1$ contingency analyses to provide backup schemes.

\section{1) Microgrids}

Voltage and frequency droop-based schemes are commonly used as part of the power management systems within a microgrid [32]. Autonomous droop-based control was primarily developed to cover integration of a wide range of generation technologies that are geographically dispersed and may connect or disconnect at anytime during islanded operation. Droop control enables power sharing among various sources without the need for a fast and wide-spread communication infrastructure. Hence, communication requirements among various devices in a microgrid become a secondary issue to access only supervisory control information as part of the overall energy management controller of a microgrid. This aspect expands the horizon of applicable communication methods to also include low speed (low-bandwidth) and intermittent communication schemes based on satellite or radio frequency media.

A microgrid may also be divided into several predefined operating zones that are autonomously independent while operating in a coordinated manner. Each zone of operation will be locally controlled and protected against system transients and contingencies. The local zones of operation may be defined according to the power quality and reliability of the loads or will be established as part of the protection coordination methodology to provide proper protection coverage and fast fault detection and clearing.

\section{2) Ships}

The ship power system is conventionally designed in a centralized fashion to achieve a high level of security and dependability. Any change in the system operation and/or energy requirements are determined by the control room and communicated to the power sources. In this environment, the communication system plays a critical role. Communication is used for both control and remote status monitoring. The protection methods may also be designed using teleprotection schemes. Although the traditional approaches were based on copper wire pilot protection, the recent designs may use Internet-based communication using DNP3 or IEC 61850 GOOSE. With the advent of renewable energy as part of the generation mix of a ship power system, the need for autonomous and decentralized control methods have been examined in recent research works [33].

\section{3) Cross-fertilization}

Distributed and autonomous control approaches provide certain merits and flexibility in design to enhance the reliability and dependability of microgrid and ship power systems. The advancement in communication technologies provides more secure and economically viable media 
choices to utilize them as part of the control and protection designs of microgrids. The use of pilot-based protection schemes and the operation experience from ship power systems will become invaluable in the selection of operation modes and protection zones within a microgrid to achieve both autonomy and visibility in the overall power and energy management of the system.

Both types of systems are going to be affected by the ubiquity of smarter systems. Passive protection may indeed provide the ultimate backup, but over the next decade it is likely that much more imbedded processing power will be incorporated, providing additional operational features and efficiencies.

This is an area where terrestrial microgrids may be leading the way, especially with the push toward the widespread installation of smart meters and the stated goal of a truly dynamic contractual relationship between energy providers and users. It is to be expected that the gradual transformation of the grid into a smart grid will be mirrored by the transformation of the ship's power system control into a smart control, to a large extent, if not completely.

In many ways, this transformation will affect all points of comparison discussed so far, but particularly points $\mathrm{C}$ through M. While predictions are always difficult, it is probable that the control of the ship's power system may never achieve the full automation potential of its landbased system counterpart due to its very special missions and characteristics. Some of these features, already touched upon in the preceding sections, are worth summarizing inasmuch as they impact the smart control of the ship power:

a. The variety of possible ship's power architectures is much more limited

b. The allowable reconfiguration options can be largely explored and tested beforehand

c. The dominance of conventional generation makes the control of the power sources more amenable to "classical" techniques

d. The potential ability of a ship power system to be designed to endure larger departures in power quality, except in few instances, calls for a control strategy that is more tolerant and elastic

e. The complete control over the loads allows more flexibility during shedding operations

f. The larger penetration of non-conventional intermittent loads translates into the management of sufficient storage capacity at the load or at the system level, which is a challenge not usually faced in microgrids

g. Except for interfacing with the shore grid, no need exists for long-term coordination with neighboring microgrids h. The control architecture is expected to be more hierarchical and centralized than what is envisioned now for future microgrids and the grid in general

i. Cybersecurity will be an overarching concern: thus, smart meters, which are potential points of attack, will be limited in their use much more than in terrestrial microgrids

j. It is likely that the ship's concepts of operation (CONOPS) will always include a much larger percentage of manual overrides than in terrestrial systems, which will have to be reflected in the control strategy.

\subsection{Simulation: part I-offline simulation types}

Simulation techniques applicable to the design and analysis of microgrids and ships are examined. Offline (i.e., on a desktop computer) time domain load flow and offline time domain electromagnetic transient analysis are two different simulation techniques used at different stages of design. The simulation types and their order are the same for microgrids and ships; hence, the following discussion is presented directly from a cross-fertilization perspective.

The increasing trend of upgrading electrical infrastructures to operate as islanded microgrids, first, requires assessing feasibility. Taking the case of a terrestrial military base as an example, to answer whether this installation can survive disconnected from the grid also requires answering for how long and under what scenarios-two questions that require simulation to estimate. While simulation plays an important role in answering these questions, the type of simulation is what dictates how fast and to what level of certainty these answers are provided.

In both microgrids and ship power systems, load flow simulation appears early in the design phase. However, it should be recognized that there is a growing difference between classical load flow and time domain load flow solutions-the latter being more important and rarely available in commercial programs today. The classical load flow solution returns the power flow of each system branch-but it only does it once by assuming a time invariant load. Time domain load flow returns the same solution, but repeatedly in intervals of typically $15 \mathrm{~min}$ $\left(O\left(10^{2}\right) \mathrm{s}\right)$. The latter load flow solution scheme allows the modeler to specify time-varying sources and loads.

Electromagnetic transient simulation [64] is a comprehensive, high-fidelity simulation technique used to assess stresses and phenomena caused by switching actions, harmonics, resonance, surges, and other high-speed dynamics. While this simulation technique assesses many metrics from a single simulation run, it is also the most computationally intense. This has commonly limited practice of this simulation technique to short time spans, reduced-order 
models [65], or average-value models [66]; however, due to the wealth of information arising from this simulation type, it is an important simulation technique and commonly used after steady-state assessments have been made [67].

It is clear that both simulations are necessary; but which simulation to use first may not be. Experience shows twotier simulation approaches work well for both microgrids and ships using, first, a steady-state or time domain load flow and, then, time domain electromagnetic transient analysis. One reason for this choice is that existing installations that will become microgrids are well designed, have operated for decades, and are mostly resilient.

Another reason is fast assessment. Steady-state simulations answer high-level questions in less time than transient analysis does. When starting from resilient systems, the question of foremost interest is whether the system can survive in island mode and for how long. This question can be answered rather quickly through time domain load flow simulations. Electromagnetic transient simulations follow by answering questions requiring scrutiny at a much higher resolution (e.g., power quality). The time resolution of this simulation type is $O\left(10^{-6}\right) \mathrm{s}$ and takes considerable time to obtain results [68].

The order in which simulations are executed on microgrids is the same for ships: a top-bottom approach starting from a steady-state solution (i.e., load flow) followed by a transient one. The top-bottom approach is well-justified in ships, as it is commonly sought to estimate fuel use over mission profiles early in the design process [69]. Additionally, line and energy conversion losses can be estimated without delving into lengthy electromagnetic simulations. This consistently maintains the simulation type and the order in which they are executed for microgrid and ship power system design practice.

\subsection{Simulation: part II-modeling synergies}

Known synergies between microgrid and ship power apparatus models are described.

\section{1) Microgrids}

Microgrids with an increased penetration of renewable energy resources and conventional generation units [70] are proliferating. Their advanced technologies and automation schemes, such as automatic network reconfiguration, distribution automation, a high penetration of renewable energy resources, and smart grid features, bring about new challenges to their modeling. In contrast, classical power system modeling (i.e., portions of the national grid), has traditionally been an aggregation of conventional technologies that could be modeled using existing models from the program libraries of various simulation tools.

Among various types of simulation, the static one-time load flow solution is the simplest-and models for this are readily available and mostly require equipment nameplate data. For time domain load flow (otherwise known as quasi-static or time series load flow), models with some additional data such as time-based generation, operation, control, and load data may be needed.

The study of dynamic and transient behavior is slightly complex and is useful when coupled with high fidelity models. Some component models for those types of simulations may not be easily available; however, the majority of them are available in the literature and are normally part of simulation tool libraries. When models for components are not readily available, generic or custom models are required to advance the simulation. This responsibility is left to the end-user.

\section{2) Ships}

Microgrids and ship power systems are closely related systems in terms of the technologies used and their models. In both cases, similar components are used for the machine-based generation, protection, distribution, and control of electrical energy (with some exceptions). Future generation ships are expected to have a higher power density and may require specialized models to include the thermal system and higher-frequency analysis.

It is expected that there will be a need for additional models that are unlikely to form part of a simulation tool's library. For example, pulsed loads are special loads required for modeling ship defense systems, but may not be required in microgrid systems [71]. Similarly, wind turbines, common in microgrids, are not present in ship systems. Despite the differences in power apparatus counts and types, when commonalities do exist (e.g., low-voltage three-phase inverters), these can be exploited by interchanging the models with minor or no modifications.

\section{3) Cross-fertilization}

There are important synergies in the models used for microgrids and ships-but there are also differences. The depth and fidelity requirement of the models can be different and depends on the intended type of simulation. For example, the models required for time domain load flows differ from the models required for electromagnetic transient simulation. Models for electromagnetic transient simulations require detailed information (e.g., nonlinearity and time variance) as compared to load flow or phasorbased simulations [72]. However, when the simulation and power apparatus types are the same for microgrids and 
ships, the models are interchangeable with minor (if any) modifications.

\section{Conclusions}

While the electrical and physical size of microgrids and ships are similar, their constraints are not. Terrestrial microgrids can be expanded as their physical footprints are of less concern. In ships, sizing is established in advance as built ships pose inflexible hull dimensions. Thus, the size and weight constraints on ships are predominant and more critical than those for terrestrial microgrids. This has motivated the ESRDC to consider alternate designs in the high-frequency AC space due to increased generation-side power density.

In microgrids, the switching equipment allows the interconnected operation to large power systems or the operation on islanded mode. So, with the purpose of maintaining acceptable protection performance, it is essential that protection schemes ensure the reliable and safe operation by using predefined setting groups, advanced settings computed online, and operational adaptation of settings of relays or reclosers [73].

Both ships and terrestrial microgrids are fields of growing technical significance. They can build, to some extent, from a common modeling base and some commonality in equipment. While both systems are expected to incorporate increased processing capability in their design, i.e., become smarter, the payoff for the advanced system appears to be more immediate in the electric ship. The constrained size and weight, the appropriate focus on extreme levels of reliability, and the need to be efficient over a wide range of operating conditions suggest that the ship will lead the development with the land-based system following. Finally, protection, stability, and power electronics are important to the future of both systems. They each have unique attributes that will likely lead to somewhat different solutions; however, the possibility of cross-fertilization in these areas is large.

Acknowledgments This work was supported by a Grant from the Office of Naval Research (ONR).

Open Access This article is distributed under the terms of the Creative Commons Attribution 4.0 International License (http://creativecommons.org/licenses/by/4.0/), which permits unrestricted use, distribution, and reproduction in any medium, provided you give appropriate credit to the original author(s) and the source, provide a link to the Creative Commons license, and indicate if changes were made.

\section{References}

[1] Market data: Microdgrids-Forecasts for commercial/industrial, community/utility, campus/institutional, military, and remote microgrids: 2013-2020. Navigant Research, Boulder, CO, USA, 2013
[2] International convention for the prevention of pollution from ship (MARPOL) Annex VI. International Maritime Organization, London, UK, 1997

[3] Savage P, Nordhaus RR, Jamieson SP (2010) DC microgrids: benefits and barriers. Yale School of Forestry \& Environmental Studies, New Haven

[4] Ton M, Fortenbery B, Tschudi W (2008) DC power for improved data center efficiency. Lawrence Berkeley National Laboratory (LBNL), Berkeley, CA, USA

[5] Pratt A, Kumar P, Aldridge TV (2007) Evaluation of 400 V DC distribution in telco and data centers to improve energy efficiency. In: Proceedings of the 29th international telecommunications energy conference (INTELE'07), Rome, Italy, 30 Sept-4 Oct 2007, pp 32-39

[6] Anand S, Fernandes BG (2010) Optimal voltage level for DC microgrids. In: Proceedings of the 36th annual conference on IEEE Industrial Electronics Society (IECON'10), Glendale, AZ, USA, 7-10 Nov 2010, pp 3034-3039

[7] Kwasinski A (2009) Evaluation of DC voltage levels for integrated information technology and telecom power architectures. In: Proceedings of the 4th international conference on telecommunication-Energy special conference (TELESCON'09), Vienna, Austria, 10-13 May 2009, 7 pp

[8] Schulz NN, Hebner RE, Dale S et al (2008) The US ESRDC advances power system research for shipboard systems. In: Proceedings of the 43rd international universities power engineering conference (UPEC'08), Padova, Italy, 1-4 Sept 2008, 4 pp

[9] Stewart HR, Stewart D, Stone F et al (2003) Panel discussion of IEEE-45-2002: IEEE recommended practice for electrical installation on shipboard. In: Proceedings of the IEEE IAS 50th annual petroleum and chemical industry conference (PCIC'03), Houston, TX, USA, 15-17 Sept 2003, pp 351-353

[10] MIL-STD 1399 Interface standard for shipboard systems, 2002

[11] IEEE Std 1709-2010 IEEE recommended practice for $1 \mathrm{kV}$ to $35 \mathrm{kV}$ medium-voltage DC power systems on ships, 2010

[12] Kwasinski A (2008) Analysis of electric power architectures to improve availability and efficiency of air conditioning systems. In: Proceedings of the IEEE 30th international telecommunications energy conference (INTELEC'08), San Diego, CA, USA, 14-18 Sept 2008, 8 pp

[13] DC protection (2011) Electric Ship Research and Development Consortium (ESRDC), Austin, TX, USA

[14] Beno JH, Hebner RE, Ouroua A (2011) High-frequency power generation and distribution in multi-megawatt power systems. In: Proceedings of the 2011 IEEE electric ship technologies symposium (ESTS'11), Alexandria, VA, USA, 10-13 Apr 2011, pp 84-89

[15] Hebner RE, Beno JH, Ouroua A (2011) Dynamic simulations of a large high-frequency power system. In: Proceedings of the 2011 grand challenges in modeling and simulation conference (GCMS'11), Hague, Netherlands, 27-30 Jun 2011, pp 129-136

[16] Pipattanasomporn M, Kuzlu M, Rahman S (2012) An algorithm for intelligent home energy management and simulation for demand response analysis. IEEE Trans Smart Grid 3(4):21662173

[17] Shao SN, Pipattanasomporn M, Rahman S (2011) Demand response as a load shaping tool in an intelligent grid with electric vehicles. IEEE Trans Smart Grid 2(4):624-631

[18] Shao SN, Pipattanasompor M, Rahman S (2012) Grid integration of electric vehicles and demand response with customer choice. IEEE Trans Smart Grid 3(1):543-550

[19] Pipattanasomporn M, Feroze H, Rahman S (2012) Securing critical loads in a PV-based microgrid with a multi-agent system. Renew Energy 39(1):166-174 
[20] Naval ships technical manual: Chapter 320-Electrical power distribution systems, Revision 2. S9086-KY-STM-010/CH320R2, Naval Sea Systems Command, Washington, DC, USA, 1998

[21] Sauer PW, Pai MA (1998) Power system dynamics and stability. Prentice Hall, Upper Saddle River

[22] Bollen MHJ, Hassan F (2011) Integration of distributed generation in the power system. Wiley, New York

[23] The international convention for the safety of life at sea (SOLAS). International Maritime Organization, London, UK, 1974

[24] Hebner RE, Gattozzi AL, Cohn KR et al (2010) Analysis of the power quality impact of multiple directed energy loads on an electric ship power system. In: Proceedings of the 23rd annual conference on solid state and diode laser technology review (SSDLTR'10), Broomfield, CO, USA, 15-18 Jun 2010, 5 pp

[25] Hebner RE, Herbst JD, Gattozzi AL (2010) Large scale simulations of a ship power system with energy storage and multiple directed energy loads. In: Proceedings of the 2010 conference on grand challenges in modeling and simulation (GCMS'10), Ottawa,Canada, 11-14 Jul 2010, pp 430-435

[26] Hebner RE, Herbst JD, Gattozzi AL (2010) Intelligent microgrid demonstrator. In: Proceedings of the 2010 American Society of Naval Engineers (ASNE) electric machines technology symposium (EMTS'10), Philadelphia, PA, USA, 19-20 May 2010, 11 $\mathrm{pp}$

[27] Feng XY (2012) A bio-inspired multi-agent system framework for real-time load management in all-electric ship power systems. Ph D Thesis, Texas A\&M University, College Station, TX, USA

[28] Feng XY, Butler-Purry KL, Zourntos T (2012) Multi-agent system-based real-time load management for all-electric ship power systems in DC zone level. IEEE Trans Power Syst 27(4):1719-1728

[29] Milligan M, Porter K, DeMeo E et al (2009) Wind power myths debunked. IEEE Power Energy Mag 7(6):89-99

[30] Jewell W (1994) Issues in utility-interactive photovoltaic generation. IEEE Power Eng Rev 14(4):19-21

[31] Ipakchi A, Albuyeh F (2009) Grid of the future. IEEE Power Energy Mag 7(2):52-62

[32] Guerrero JM, Vasquez JC, Mata J et al (2011) Hierarchical control of droop-controlled AC and DC microgrids-a general approach toward standardization. IEEE Trans Ind Electron 58(1):158-172

[33] Feng XY, Butler-Purry KL, Zourntos T et al (2011) Multi-agent system-based real-time load management for NG IPS ships in high/medium voltage level. In: Proceedings of the 2011 IEEE/ PES power systems conference and exposition (PSCE'11), Phoenix, AZ, USA, 20-23 Mar 2011, 8p

[34] Hirose K, Takeda T, Muroyama S (2006) Study on field demonstration of multiple power quality levels system in Sendai. In: Proceedings of the 28th annual international telecommunications energy conference (INTELEC'06), Providence, RI, USA, 10-14 Sept 2006, 6p

[35] Kwasinski A, Onwuchekwa CN (2011) Dynamic behavior and stabilization of DC microgrids with instantaneous constantpower loads. IEEE Trans Power Electron 26(3):822-834

[36] Kwasinski A, Krein PT (2007) Passivity-based control of buck converters with constant-power loads. In: Proceedings of the IEEE 38th power electronics specialists conference (PESC'07), Orlando, FL, USA, 1-21 Jun 2007, pp 259-265

[37] Kwasinski A, Krein PT (2007) Stabilization of constant power loads in DC-DC converters using passivity-based control. In: Proceedings of the 29th international telecommunications energy conference (INTELEC'07), Rome, Italy, 30 Sept-4 Oct 2007, pp 867-874
[38] Onwuchekwa CN, Kwasinski A (2010) Analysis of boundary control for buck converters with instantaneous constant-power loads. IEEE Trans Power Electron 25(8):2018-2032

[39] Onwchekwa CN, Kwasinski A (2011) Analysis of boundary control for buck converters with instantaneous constant-power loads. In: Proceedings of the 26th IEEE annual applied power electronics conference and exposition (APEC'11), Fort Worth, TX, USA, 6-11 Mar 2011, pp 1816-1823

[40] Lasseter RH, Paigi P (2004) Microgrid: a conceptual solution. In: Proceedings of the 35th IEEE annual power electronics specialists conference(PESC'04), Vol 6, Aachen, Germany, 20-25 Jun 2004, pp 4285-4290

[41] Coelho EAA, Cortizo PC, Garcia PFD (2002) Small-signal stability for parallel-connected inverters in stand-alone $\mathrm{AC}$ supply systems. IEEE Trans Ind Appl 38(2):533-542

[42] De Brabandere K, Bolsens B, Van den Keybus J (2007) A voltage and frequency droop control method for parallel inverters. IEEE Trans Power Electron 22(4):1107-1115

[43] Kundu P (1994) Power system stability and control. McGrawHill Professional, New York

[44] Gautam D, Vittal V, Harbour T (2009) Impact of increased penetration of DFIG-based wind turbine generators on transient and small signal stability of power systems. IEEE Trans Power Syst 24(3):1426-1434

[45] Van Cutsem T, Vournas C (2007) Voltage stability of electric power systems, 2nd edn. Springer, New York

[46] Woodruff SL, Qi L, Sloderbeck MJ (2007) Hardware-in-theloop experiments on the use of propulsion motors to reduce pulse-load system disturbance. In: Proceedings of the 2007 IEEE electric ship technologies symposium (ESTS'07), Arlington, VA, USA, 21-23 May 2007, pp 455-461

[47] Rivetta CH, Emadi A, Williamson GA (2006) Analysis and control of a buck DC-DC converter operating with constant power load in sea and undersea vehicles. IEEE Trans Ind Appl 42(2):559-572

[48] Kwasinski A, Krein PT (2005) A microgrid-based telecom power system using modular multiple-input DC-DC converters. In: Proceedings of the 27 th international telecommunications energy conference (INTELEC'05), Berlin, Germany, 18-22 Sept 2005, pp 515-520

[49] Kwasinski A (2009) Identification of feasible topologies for multiple-input DC-DC converters. IEEE Trans Power Electron 24(3):856-861

[50] Kwasinski A (2011) Quantitative evaluation of DC microgrids availability: effects of system architecture and converter topology design choices. IEEE Trans Power Electron 26(3):835-851

[51] Anwar A, Zhang YC, Dougal RA (2012) Soft restarting of industrial power network using inverter-controlled energy storage system. In: Proceedings of the 2012 IEEE Power and Energy Society general meeting, San Diego, CA, USA, 22-26 Jul 2012, $8 \mathrm{pp}$

[52] Taylor CW (1992) Concepts of undervoltage load shedding for voltage stability. IEEE Trans Power Deliv 7:480-488

[53] Adibi MM, Milanicz DP (1995) Protective system issues during restoration. IEEE Trans Power Syst 10(3):1492-1497

[54] Srivastava SK, Butler-Purry KL (2005) A pre-hit probabilistic reconfiguration methodology for shipboard power systems. In: Proceedings of the 2005 IEEE electric ship technologies symposium (ESTS'05), Philadelphia, PA, USA, 25-27 Jul 2005, pp 99-104

[55] Cairoli P, Kondratiev I, Dougal RA (2013) Coordinated control of the bus tie switches and power supply converters for fault protection in DC microgrids. IEEE Trans Power Electron 28(4):2037-2047

[56] Cairoli P, Kondratiev I, Dougal RA (2011) Controlled power sequencing for fault protection in DC nanogrids. In: Proceedings 
of the 2011 IEEE international conference on clean electrical power (ICCEP'11), Ischia, Italy, 14-16 Jun 2011, pp 730-737

[57] Cairoli P, Dougal RA, Ghisla U et al (2010) Power sequencing approach to fault isolation in DC systems: Influence of system parameters. In: Proceedings of the 2010 IEEE energy conversion congress and exposition (ECCE'10), Atlanta, GA, USA, 12-16 Sept 2010, pp 72-78

[58] IEEE Std 142-2007 (2007) IEEE recommended practice for grounding of industrial and commercial power systems

[59] IEEE Std 45-1983 (1983) IEEE recommended practice for electrical installations on shipboard

[60] Jacobson R, Walker J (2007) Grounding considerations for DC and mixed DC and AC power systems. Nav Eng J 119(2):49-62

[61] Infante D, Langston J, Graber L et al (2011) Guiding the selection of physical experiments supporting validation of electric power system models. In: Proceedings of the 2011 grand challenges in modeling and simulation conference (GCMS'11), Hague, Netherlands, 27-30 Jun 2011, pp 173-180

[62] Pan Y, Steurer M, Baldwin TL (2011) Ground fault location testing of a noise-pattern-based approach on an ungrounded DC system. IEEE Trans Ind Appl 47(2):996-1002

[63] Katiraei F, Iravani MR (2006) Power management strategies for a microgrid with multiple distributed generation units. IEEE Trans Power Syst 21(4):1821-1831

[64] Dommel HW (1969) Digital computer solution of electromagnetic transients in single - and multiphase networks. IEEE Trans Power Appar Syst 88(4):388-399

[65] Uriarte FM, Hebner R (2011) Development of a multicore power system simulator for ship systems. In:Proceedings of the 2011 IEEE electric ship technologies symposium (ESTS'11), Alexandria, VA, USA, 10-13 Apr 2011, pp 106-110

[66] Krause PC, Wasynczuk O, Sudhoff SD (2002) Analysis of electric machinery and drive systems, 2nd edn. IEEE Press, Piscataway

[67] Uriarte FM, Hebner RE, Gattozzi AL (2011) Accelerating the simulation of shipboard power systems. In: Proceedings of the 2011 grand challenges in modeling and simulation conference (GCMS'11), Hague, Netherlands, 27-30 Jun 2011, pp 22-29

[68] Uriarte FM (2011) Multicore simulation of an ungrounded power system. IET Electr Syst Transp 1(1):31-40

[69] ESRDC Electrical Integrated Product Team (2012) Modeling of shipboard power systems. In: Proceedings of the 10th anniversary meeting on electric ship research and development consortium (ESRDC'12), Austin, TX, USA, 4-6 Jun 2012

[70] Chowdhury S, Chowdhury SP, Crossle P (2009) Microgrids and active distribution networks. Institution of Engineering and Technology, Stevenage

[71] Langston J, Steurer M, Crider J et al (2012) Waveform-level time-domain simulation comparison study of three shipboard power architectures. In: Proceedings of the 2012 summer computer simulation conference (SCSC'12), Genoa, Italy, 8-11 Jul 2012, pp 485-492

[72] Grover JD, Sharma MS, Overbye TJ (2008) Power system analysis and design, 4th edn. Thomson Learning, Pacific Grove

[73] Abdulhadi I, Coffele F, Dyśko A et al (2011) Adaptive protection architecture for the smart grid. In: Proceedings of the IEEE PES 2nd international conference and exhibition on innovative smart grid technologies (ISGT Europe'11), Manchester, UK, 5-7 Dec 2011, 8 pp

Robert E. HEBNER PhD is Director of the Center for Electromechanics at the University of Texas at Austin. The Center develops technology, primarily for novel motors, generators, and suspension components, and teams with companies to get the technology into the market. Previously, Dr. Hebner was the acting Director of the US National Institute of Standards and Technology (NIST). In addition, he has directed NIST's Electronic and Electrical Engineering Laboratory, a laboratory with a staff of more than 250 . He also worked at the Defense Advanced Research Projects Agency where he developed programs to improve semiconductor manufacturing. Throughout his career, Dr. Hebner has been active in having authored or coauthored more than 150 technical papers and reports. He has extensive experience in international technology programs. This work included the modernization of the measurement systems needed to support global trade and the assessment of the effectiveness of government technology programs in stimulating domestic economies.

Fabian M. URIARTE $\mathrm{PhD}$ is a Research Associate at the Center for Electromechanics at the University of Texas at Austin. He obtained his BSc and MSc from Virginia Tech in power systems and his $\mathrm{PhD}$ from Texas A\&M University in parallel electromagnetic transient simulation of ship power systems. His research interests include modeling, analysis, and simulation of power systems, distribution systems, microgrids, and smart grids. He is a simulation specialist and currently leads the smart grid simulation effort for the Pecan Street Project.

Alexis KWASINSKI PhD is an Assistant Professor in the Department of Electrical and Computer Engineering at the University of Texas at Austin. He obtained his $\mathrm{MS}$ and $\mathrm{PhD}$ in electrical engineering from the University of Illinois at Urbana-Champaign. His past industry experience includes working for Telefónica of Argentina and for Lucent Technologies Power Systems. His research interests include power electronics, distributed generation, renewable and alternative energy, smart grids, and analysis of the impact of natural disasters on critical power infrastructure. In 2005, he was awarded the INTELEC Fellowship and in 2007 he received the best technical paper award at INTELEC. In 2009 he received an NSF CAREER award. Dr. Kwasinski is an Associate Editor for the IEEE Transactions on Energy Conversion.

Angelo L. GATTOZZI PhD is a Research Associate at the Center for Electromechanics at the University of Texas at Austin where he has been working on power modules for the electric gun program, resonant converters for high speed motors/generators with flywheel energy storage, energy harvesting from sea waves, and simulations for the electric system of the DDG51 class Navy destroyer. Prior to joining the University of Texas, he was responsible, at the Lincoln Electric Company in Cleveland, Ohio, for the development of a complete new line of induction motors, achieving the highest efficiency levels in the industry.

Hunter B. ESTES MSc is a received his BS degree in chemical engineering and MS degree in electrical engineering from the University of Texas at Austin in 1997 and 2011, respectively. He is currently working toward the $\mathrm{PhD}$ degree in electrical and computer engineering, and is a Research Assistant, at the Center for Electromechanics at the University of Texas at Austin. His research group is Energy Systems, under the guidance of Dr. Alexis Kwasinski and Dr. Robert E. Hebner. His interests are in solar generation, as well as smart grid energy management.

Asif ANWAR received his MS degree from the department of Applied Physics and Electronics from the University of Dhaka, Bangladesh, in 2005 with a Major in Power Electronics. Previously, he received his BSc (Hons) in 2003 from the same department. He is currently working toward his PhD degree at the University of South 
Carolina. His research interests includes controls for energy storage inverter for terrestrial and ship power systems, and development of controls for utility scale or dispersed energy storage systems to mitigate power quality issues during system disturbances.

Pietro CAIROLI received the Dr. Eng. Degree and MS degree in Electrical Engineering in 2010 from the Politecnico di Milano, Milan, Italy. $\mathrm{He}$ is currently pursuing the $\mathrm{PhD}$ degree in Electrical Engineering at the University of South Carolina, Columbia, SC. His current research interests include DC distribution system analysis and protection, simulation models, power electronics, and embedded control for power management in distribution systems.

Roger A. DOUGAL $\mathrm{PhD}$ received the $\mathrm{PhD}$ degree in electrical engineering from Texas Tech University, Lubbock, in 1983. He is currently the Thomas Gregory Professor of Electrical Engineering at the University of South Carolina, Columbia, where he leads the Power and Energy Systems Group. He is a Director of the Electric Ship Research and Development Consortium (ESRDC), which is developing electric power technologies for the next generation of electric ships, he is co-director of the NSF Industry/University Cooperative Research Center for Grid-connected Advanced Power Electronic Systems, and he leads development of the Virtual TestBed-a computational environment for simulation-based-design and virtual prototyping of dynamic, multidisciplinary systems. His research interests include power electronics, hybrid power sources, and simulation methods.

Xianyong FENG $\mathrm{PhD}$ received the $\mathrm{PhD}$ degree in the Department of Electrical and Computer Engineering at Texas A\&M University, College Station, in 2012. He is currently with ABB Inc., U.S. Corporate Research Center, Raleigh, NC. His industrial experience also includes an internship with ExxonMobil Upstream Research Company in summer 2010. His research interests are in the areas of EMS and secondary control of finite inertia power systems, microgrids, consensus and cooperative control, and applications of linear and nonlinear system theories.

Hung-Ming CHOU received his BS degree in Electrical Engineering in 2004 in National Chiao Tung University in Taiwan. He received his MS degree in Electrical and Computer Engineering in 2009 from Texas A\&M University. He joined the PhD program in Power System Automation Lab in the same department in 2009. His research interests include power electronics, power system dynamics and control, renewable energy integration, and hardware-in-the-loop real time simulation.

Laurence J. THOMAS received his BS from Prairie View A\&M University, Prairie View, TX, in 2005, and obtained his MS at Texas A\&M University, College Station, TX, in 2010 in electrical engineering. He is currently an Associate Electrical Engineer at Lauren Engineers \& Constructors, Inc. His company is an engineering, construction, and procurement company that designs and builds power plants and concentrated solar plants. He is part of the electrical department design team that designs and analyzes electrical systems in power plants and green energy plants such as concentrated solar combined cycle plants in the United States. He is currently involved in the first $50 \mathrm{MW}$ concentrated solar plant installation in Rajasthan, India.

Manisa PIPATTANASOMPORN PhD joined Virginia Tech's Department of Electrical and Computer Engineering as an assistant professor in 2006. She manages multiple research grants from the U.S. National Science Foundation, the U.S. Department of Defense and the U.S. Department of Energy, on research topics related tosmart grid, microgrid, energy efficiency, load control, renewable energy and electric vehicles. She received her $\mathrm{PhD}$ in electrical engineering from Virginia Tech in 2004, the MS degree in Energy Economics and Planning from Asian Institute of Technology (AIT), Thailand in 2001 and a BS degree from the Electrical Engineering Department, Chulalongkorn University, Thailand in 1999. Her research interests include renewable energy systems, energy efficiency, distributed energy resources, and the smart grid.

Saifur RAHMAN $\mathrm{PhD}$ is the Director of the Advanced Research Institute at Virginia Tech where he is the Joseph Loring Professor of Electrical and Computer Engineering. He also directs the Center for Energy and the Global Environment at the university. In 2012 he is serving as the Vice President for Publications of the IEEE Power \& Energy Society and a member of its Governing Board. He is a member-at-large of the IEEE-USA Energy Policy Committee and currently the chair of the U.S. National Science Foundation Advisory Committee for International Science and Engineering. Between 1996 and 1999 he served as a program director in engineering at NSF. In 2006 he served as the vice president of the IEEE Publications Board, and a member of the IEEE Board of Governors. He is a distinguished lecturer of IEEE PES, and has published in the areas of smart grid, conventional and renewable energy systems, load forecasting, uncertainty evaluation, and infrastructure planning.

Farid KATIRAEI $\mathrm{PhD}$ is a Principal Advisor with Quanta Technology in the area of renewable energy and power system protection. His main area of interest is advanced automation and application of power electronics and decentralized energy systems for new system architectures including microgrids and smart grids. Prior to joining Quanta, Dr. Katiraei was with the Natural Resources Canada Energy Research Center (CANMETEnergy) in VarennesQuébec where he was involved in control and protection system design, grid interconnection assessment, transient modeling, and field testing of distributed and renewable energy resources. Dr. Katiraei received his $\mathrm{PhD}$ degree in electrical engineering from the University of Toronto (Toronto, Canada) in 2005. He is a senior member of IEEE, editor of IEEE Transactions on Power Delivery, and the steering committee member of international collaboration on Microgrids.

Michael STEURER PhD received a Master of Electrical Engineering in 1995 from the Vienna University of Technology and his PhD in Technical Science in 2001 from the Swiss Federal Institute of Technology. Dr. Steurer is currently a senior researcher at the Florida State University Center for Advanced Power Systems where he leads the power systems group focusing on HIL simulation and modeling of integrated power systems for all-electric ships and future terrestrial power systems. Dr. Steurer has authored or coauthored more than 100 technical papers in electric power apparatus and their system interactions and is a member of CIGRE.

M. Omar FARUQUE $\mathrm{PhD}$ obtained his $\mathrm{PhD}$ from the University of Alberta, Canada in 2008. He is currently working as an Assistant Scholar Scientist at the Center for Advanced Power Systems at the Florida State University in Tallahassee, FL, USA. His research interests are in the area of hardware-in-the-loop simulation, modeling and simulation of FACTS, HVDC and renewable resources, and Distributed Resources Interconnection and their impacts on electrical systems.

Mario A. RÍOS PhD received a BS degree in electrical engineering in 1991 and an M.Sc. degree in electrical engineering in 1992, both from Universidad de los Andes, Bogotá, Colombia. He received a $\mathrm{PhD}$ degree in electrical engineering from INPG-LEG, France, in 
1998, and a Doctoral degree in engineering from Universidad de los Andes, in 1998. He worked as a consultant engineer in ConCol, Bogotá, Colombia, for 12 years. Also, he was a Research Associate at the University of Manchester (formerly, UMIST). Currently, he is Associate Professor in the Department of Electrical Engineering, School of Engineering, Universidad de Los Andes, Bogotá, and director of the Power and Energy Group of this university.

Gustavo A. RAMOS received a BS degree in electrical engineer (1997) from Universidad Nacional, Manizales, Colombia and M.Sc. (1999) and $\mathrm{PhD}$ (2008) in electrical engineering from Universidad de Los Andes, Bogotá, Colombia. Currently, he is Assistant Professor in the Department of Electrical Engineering, School of Engineering, Universidad de Los Andes, Bogotá.

Mirrasoul J. MOUSAVI PhD is a Principal Scientist Engineer with ABB U.S. Corporate Research Center. He received his PhD degree in electrical engineering from Texas A\&M University in 2005. He was a researcher in the Power System Automation Laboratory and a graduate lecturer at Texas A\&M University prior to joining ABB.
From 1999 to 2001, he was with Niroo Research Institute (NRI) as an R\&D Engineer. Dr. Mousavi is a member of IEEE, IEEE Power and Energy Society (PES), and IEEE Dielectrics and Electrical Insulation Society (DEIS). His current professional interests are related to power system automation, data analytics, and power system modeling and simulation.

Timothy J. MCCOY $\mathrm{PhD}$ has 30 years experience working in government, industry and academia. His expertise includes program management, power systems and control systems engineering, marine engineering, ship design and construction, technology development, operations as well as education and training. $\mathrm{He}$ is an expert in the design, development and fielding of complex systems for both military and commercial applications. He has successfully created and led new technology development organizations in both industry and government. Dr. McCoy is an internationally recognized expert in finite inertia power systems who holds an adjunct faculty position at Carnegie Mellon University, is a Licensed Professional Engineer and is widely published. 